\title{
ПУТИ СОВЕРШЕНСТВОВАНИЯ МЕХАНИЗМА УПРАВЛЕНИЯ ЭЛЕКТРОЭНЕРГЕТИЧЕСКОЙ ИНФРАСТРУКТУРЫ СОГДИЙСКОЙ ОБЛАСТИ ТАДЖИКИСТАНА
}

\author{
Хомидова Машхура Исматджоновна, ассистент кафедры Электроснабжения Горно- \\ металлургического института Таджикистана, г.Бустон, Республика Таджикистан \\ DOI: https://doi.org/10.31435/rsglobal_conf/25122020/7304
}

\begin{abstract}
The article discusses the ways of improving the management of the electric power production infrastructure of the Sughd region. The results of generation and consumption of electric energy in the region are presented. The current problems of development in the management of electric networks in the region are characterized. It was revealed that the level of economic development is directly related to the level of energy efficiency. The specificity of the influence of the efficiency of the energy sector on the regional economy is revealed. It is analyzed that the electric power infrastructure plays a key role in the development of the region. Economic development depends on the potential energy reserves in the region. Which certainly affects the growth of the economy in the country. The ways of optimization of the structure of power grids control are revealed. The directions of improving the functioning of the electric grid complex of the Sughd region are proposed: the modernization of the energy infrastructure on the Smart Grid platform.
\end{abstract}

Keywords: management of the electric power infrastructure of the region, the level of energy efficiency.

Введение. Электроэффективность сегодня - это необходимое условие конкурентоспособности стран в мировой экономике, выполнение которого обеспечивается путем внедрения современных технологий, модернизации всех сфер хозяйственной деятельности, экологии, образа жизни и мышления каждого человека.

Энергетический сектор играет важнейшую роль в экономическом развитии Таджикистана. Доля энергетических затрат в общем объеме ВВП составляет 60\%. При этом, изза отсутствия собственных источников, Таджикистан покрывает около $70 \%$ своих потребностей в топливных ресурсах за счет дорогостоящего импорта. На развитие топливно-энергетического комплекса ежегодно выделяется более $15 \%$ всего госбюджета страны или более 300 млн. долларов США.[1]

Таджикистан является одним из мировых лидеров по потенциальным запасам гидроэнергоресурсов, занимая первое место в мире по удельным запасам на единицу территории. В настоящее время, гидроресурсы обеспечивают более $90 \%$ потребностей страны в электроэнергии.

Республика Таджикистан не обладает значительными разведанными запасами нефти и газа, основных современных источников энергии. Страна имеет существенные для неё запасы угля, основные месторождения которого расположены в труднодоступных высокогорных районах. Добыча угля и его транспортировка автомобильным транспортом, высокие производственные издержки, существенно повышают его себестоимость для населения.

Целью написания статьи заключается в выявлении пути совершенствования управления электроэнергетической производственной инфраструктуры Согдийской областы Таджикистана. Потому что, гидроэлектроэнергия в Таджикистане имеет сезонный характер. Самый низкий уровень выработки наблюдается в осенне-зимний период, когда страна испытывает значительный дефицит и вынуждена вводить жесткие ограничения по поставкам электроэнергии, которые особенно сильно отражаются на сельском населении. До 2017 года в зимние месяцы доступ к электроэнергии были ограничены до 3 часов в сутки. При этом 70\% населения страны, проживающих в сельской местности, потребляет только $9 \%$ от общего объема поставок электроэнергии потребителям [1]. Надежное энергоснабжение исключительно важно для обеспечения продовольственной безопасности и экономического развития страны. Ежегодно, по причине ограниченной подачи электроэнергии в сельской местности потеря урожайности сельхоз продукции составляет порядка 30\% и вынуждены останавливать производство около 850 средних и малых предприятий. 
Метод исследования. Необходимо отметить, что Согдийская область Республики Таджикистан с населением 2,658 млн. чел. (2019 год) [2] находится на севере Республики Таджикистана и связан с энергосистемой республики с одной линии 500кВ мощностью 501 МВА.

Относительно высокие темпы развития экономики характерны для Согдийской и Хатлонской областей, что за последние пять лет ВРП на душу населения как в целом по республике, так и по регионам систематически увеличивался. Этот показатель в рассматриваемый период в целом по республике увеличился на 48\%, в ГБАО - на 94\%; по Согдийской области - на $47 \%$ [3].

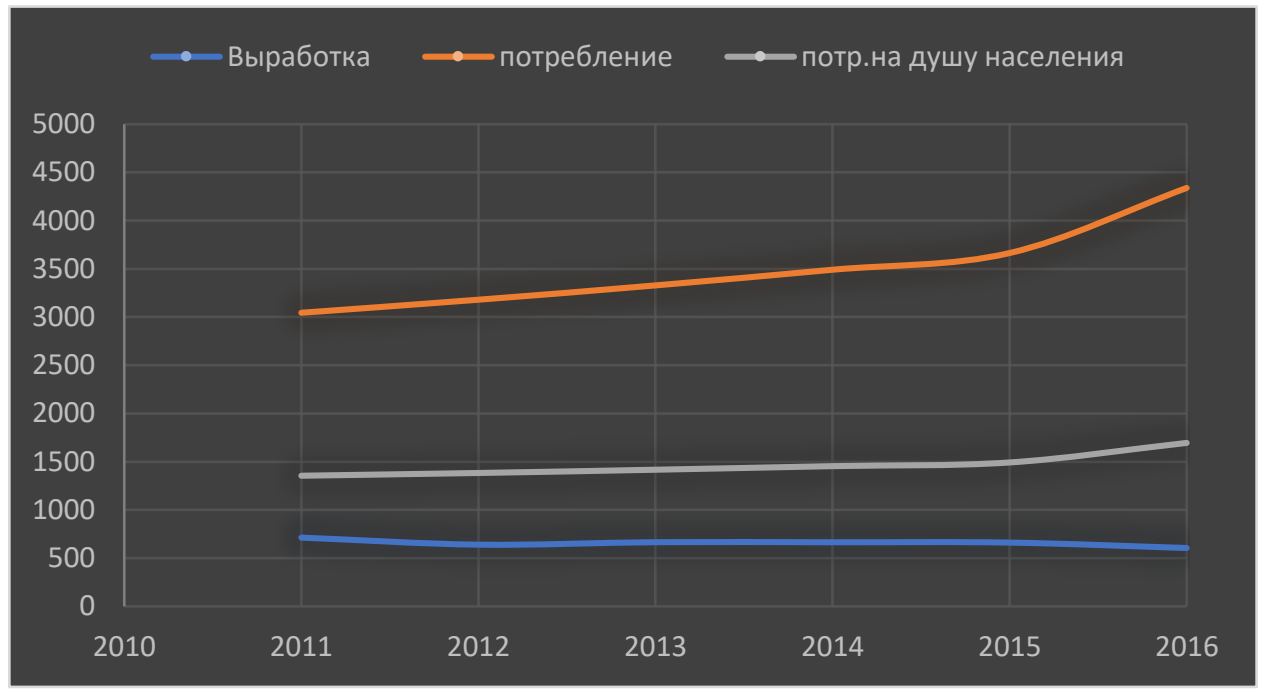

Рис.1. Производство и потребление электрической энергии Согдийской области РТ 2011 2016 г2., млн. кВт. ч. Составлено по [4].

Так как видно из графика потребление электроэнергии в регионе сравнительно выше, чем производства электроэнергии. Развитие региона зависит от их доступа к электрической энергии. Поэтому для дальнейшего развития региона необходимо развивать нынешнюю структуру управления, найти дальнейшие пути развития региона и выявить новые источники электроэнергетических потенциалов.

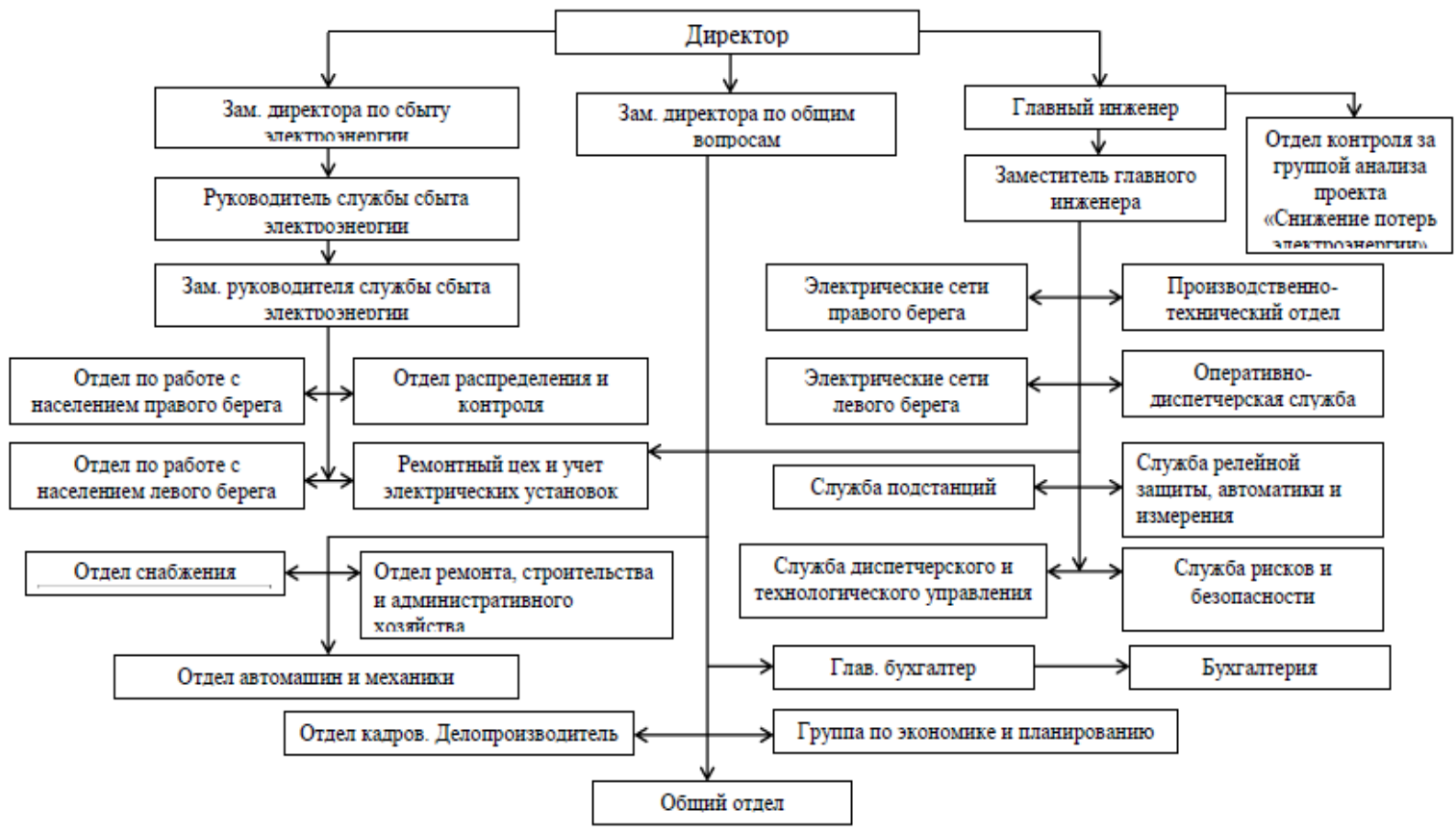

Рис.2. Структура управления электрических сетей по города Худжанда Согдийской области

В этом контексте оптимизации структура управления эклектических сетями в экономике Республики Таджикистан играет также немаловажное значение. Поскольку наличие специализированных отделов исполняющих, разрабатывающие и реализующих инновации по 
повышению энергоэффективности в энергетическом комплексе на текущем этапе развития человеческой цивилизации становятся главным. Здесь проанализируем структуру управления энергетических сетей на примере г. Худжанда Согдийской области. Как видно из рисунка 2 управления поставками электроэнергии населению осуществляется в рамках сложной структуры, имеющей дифференциацию по региональному признаку. Вместе с тем в представленной структуре отсутствуют подразделения, в функциях которых очевидно и однозначно проявлялась бы инновационная направленность. В связи с этим и инновационная деятельность всей структуры в целом не может быть достаточно эффективной, что и проявляется на практике, когда данная структура реализует те инновации, которые внедряются «сверху», централизованно по всей республике, а сама не проявляет инновационной инициативы. При этом многие инновационные формы распределения энергии, в частности формы энергосбережения могут быть внедрены на местах.

Значительную роль в реализации государственной энергосберегающей политики играют государственные программы поддержки промышленного сектора. Прежде всего это относится к программам технического развития, разрабатываемым правительственными органами совместно с крупнейшими национальными и транснациональными промышленными корпорациями. В частности, эти программы относятся к энергетическим отраслям, ускоренному развитию наукоемких промышленных производств с относительно низким удельным потреблением энергетических ресурсов, созданию и внедрению малоотходных и безотходных технологий, комплексному использованию сырья и увеличению использования отходов производств для утилизации энергии. За рубежом большие масштабы приняли различные формы государственного регулирования, использующие в качестве стимулов налоговые и амортизационные льготы, субсидии и льготные кредиты. Особую роль играет экономическое стимулирование потребителей энергоресурсов - промышленных предприятий.

В результате проведения анализа выявлена одным из приоритетных направлений совершенствования функционирования электросетевого комплекса Согдийской области, может стать модернизация энергетической инфраструктуры на платформе Smart Grid.

Smart Grid - это модернизированные сети электроснабжения, которые используют информационные и коммуникационные технологии для сбора информации об энергопроизводстве и энергопотреблении, что позволяет автоматически повышать эффективность, надѐжность, экономическую выгоду, а также устойчивость производства и распределения электроэнергии. Кроме того, умные сети позволят эффективно интегрировать централизованную и малую распределенную энергетику и достичь максимального системного экономического и технического эффекта от их использования. Сокращению потерь электроэнергии может поспособствовать развитие малой распределенной энергетики (МРЭ). Концепция МРЭ подразумевает наличие множества различных потребителей, производящих тепловую и электрическую энергию для собственных нужд, а также направляющих ее излишки в общую электрическую или тепловую сеть. МРЭ обеспечит существенный выигрыш в цене на электроэнергию, позволит снизить электроемкость производства за счет сокращения потерь электроэнергии при ее транспортировке по сетям, повысит надежность энергоснабжения [5]. Smart Grid обеспечит гибкое управление процессами потребления электроэнергии и непосредственное участие потребителей в оказании услуг уже самой централизованной системой энергоснабжения [6].

Решение проблемы привлечения дополнительных инвестиций без неоправданного повышения тарифов возможно при помощи внедрения метода стимулирования надежности и качества энергоснабжения, применение которых демонстрируют такие страны как: Великобритания, Италия, Норвегия и ряд других [7]. Данный метод заключается в следующем. На основе учета международных показателей качества электроснабжения потребителей, распределительные компании получают поощрение в виде дополнительной надбавки в тарифе, если их работа велась эффективно, и платят штраф в противном случае. Величины дополнительной платы, взимаемой с потребителей за высокое качество электроснабжения и компенсационной выплаты для них в противном случае определяются посредством выявления желания потребителей платить за улучшение (WTP — willingness to pay) и их желания принимать компенсацию (WTA - willingness to accept) того или иного размера.

На Западе широкое распространение получило государственное регулирование энергосбережения посредством налоговой политики, как правило, с применением налоговых скидок с сумм, направляемых на проведение (Научно-исследовательские и опытноконструкторские работы) НИОКР по энергосбережению. В США, Японии и 
западноевропейских странах есть государственные органы, с помощью которых усиливается или ослабляется вмешательство государства, изменяются приоритеты определенных элементов хозяйственного механизма энергосбережения и отдельных его направлений.

В зарубежной практике для оптимизации соотношения «тариф-качество» электроснабжения используются следующие показатели эффективности работы энергосистемы: индекс средней продолжительности отключений подачи электроэнергии в системе (CAIDI - Customer Average Interruption Duration Index), который позволяет судить о продолжительности перебоев электроснабжения и скорости их устранения; индекс средней частоты отключений в системе (SAIFI - System Average Interruption Frequency Index), который показывает, сколько раз в году возникали перебои электроснабжения среднестатистического потребителя, и если какие-то потребители пострадали более одного раза, то каждое отключение рассматривается как независимое; индекс средней продолжительности

В Республике Таджикистан и в регионе в настоящее время не используются никакие из этих энергоэффективных управлений.

Уровень экономического развития непосредственно связан с уровнем энергетической эффективности. Специфика влияния эффективности работы энергетического сектора на экономику региона заключается в следующем: электросетевая инфраструктура играет роль катализатора экономического развития региона. Совершенствование электросетевой инфраструктуры благотворно влияет на экономику региона, а затруднение доступа к ней или ее отсутствие затормаживает экономический рост и может способствовать износу основных фондов и, как следствие, увеличению потерь, прерываний поставок электроэнергии, низкому качеству энергоснабжения. Для повышения энергетической эффективности и ускорения экономического роста необходимо совершенствование управления электросетевыми комплексами, которое целесообразно осуществлять в следующих направлениях: консолидация активов территориальных сетевых организаций; применение метода RAB-регулирования; технологическое обновление электросетевой инфраструктуры на платформе Smart Grid; внедрение новых методов учета качества и надежности электроснабжения потребителей, обеспечивающих повышение эффективности деятельности ТСО.

\section{REFERENCES}

1. The main objectives of the Republic of Tajikistan in the framework of the UN initiative "Sustainable Energy for All". Electronic resource. Date of treatment 12/19/2020.

2. Annual statistical collection of the Republic of Tajikistan. Agency on Statistics under the President of the Republic of Tajikistan. - Dushanbe, 2019.

3. Economic mechanisms of sustainable energy development of the Republic of Tajikistan dissertation for the academic. Art. Cand. econom. sciences. Dushanbe, 2019, p. 139.

4. State Committee for Investments and State Property Management of the Republic of Tajikistan (RT). [Report on the state of foreign aid. - Dushanbe: 2014, 2015 - 104s.];

5. Inshakov OV, Bogachkova L.Yu., Oleinik O.S. Improving energy efficiency in the context of Russia's accession to the WTO: problem, interregional comparisons, solutions // Modern Economy: Problems and Solutions. 2013. No. 1. P. 17 - 32.

6. Novoselova O. How Distributed Generation and Smart Grid Will Help Each Other. [Electronic resource]. Retrieved from: http www.energyland.info/analitic - show- 96740 (date of access: 12/18/2020).

7. Sakharova I.V. Overcoming the trend of growing shortfalls in income from the transportation of electricity through the distribution networks of the region: author. dis. for the degree of Cand. econom. sciences. Volgograd, 2013. 